\title{
Correction to: The synergistic effect of mefenamic acid with ionizing radiation in colon cancer
}

\author{
Seyed Jalal Hosseinimehr ${ }^{1}$ (D) Zahar Safavi $^{1} \cdot$ Sahar Kangarani Farahani ${ }^{1} \cdot$ Zohreh Noaparast $^{1} \cdot$ Arash Ghasemi $^{2}$. \\ Hossein Asgarian-Omran ${ }^{3,4}$
}

Published online: 25 June 2019

(C) Springer Science+Business Media, LLC, part of Springer Nature 2019

\section{Correction to: Journal of Bioenergetics and Biomembranes https://doi.org/10.1007/s10863-019-09792-w}

The original version of this article unfortunately contained a mistake. The name of "Zohreh Noaparast" is now corrected in the author group of this article.

Pulisher's note Springer Nature remains neutral with regard to jurisdictional claims in published maps and institutional affiliations

The online version of the original article can be found at https://doi.org/ 10.1007/s10863-019-09792-w

Seyed Jalal Hosseinimehr

sjhosseinim@yahoo.com; sjhosseinim@mazums.ac.ir

1 Department of Radiopharmacy, Faculty of Pharmacy, Pharmaceutical Sciences Research Center, Mazandaran University of Medical Sciences, Sari, Iran

2 Department of Radiology and Radiation Oncology, Faculty of Medicine, Mazandaran University of Medical Sciences, Sari, Iran

3 Department of Immunology, School of Medicine, Mazandaran University of Medical Sciences, Sari, Iran

4 Immunogenetics Research Center, School of Medicine, Mazandaran University of Medical Sciences, Sari, Iran 